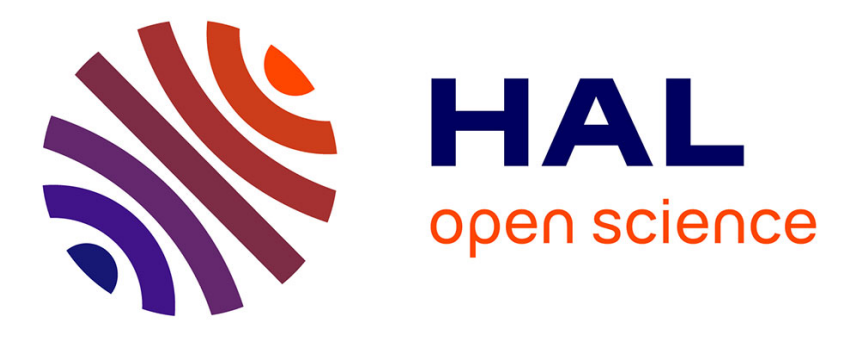

\title{
Endoparasites in the endangered Fennoscandian population of arctic foxes ()
}

Tomas Meijer, Roland Mattsson, Anders Angerbjörn, Eva Osterman-Lind, Xavier Fernández-Aguilar, Dolores Gavier-Widén

\section{- To cite this version:}

Tomas Meijer, Roland Mattsson, Anders Angerbjörn, Eva Osterman-Lind, Xavier Fernández-Aguilar, et al.. Endoparasites in the endangered Fennoscandian population of arctic foxes (). European Journal of Wildlife Research, 2011, 57 (4), pp.923-927. 10.1007/s10344-011-0505-2 . hal-00669044

\section{HAL Id: hal-00669044 https://hal.science/hal-00669044}

Submitted on 11 Feb 2012

HAL is a multi-disciplinary open access archive for the deposit and dissemination of scientific research documents, whether they are published or not. The documents may come from teaching and research institutions in France or abroad, or from public or private research centers.
L'archive ouverte pluridisciplinaire HAL, est destinée au dépôt et à la diffusion de documents scientifiques de niveau recherche, publiés ou non, émanant des établissements d'enseignement et de recherche français ou étrangers, des laboratoires publics ou privés. 


\title{
Endoparasites in the endangered Fennoscandian population of arctic foxes (Vulpes lagopus)
}

\author{
Tomas Meijer • Roland Mattsson • Anders Angerbjörn • \\ Eva Osterman-Lind • Xavier Fernández-Aguilar • \\ Dolores Gavier-Widén
}

Received: 17 December 2009/Revised: 19 January 2011 / Accepted: 24 January 2011 /Published online: 11 February 2011

(C) Springer-Verlag 2011

\begin{abstract}
The Fennoscandian arctic fox (Vulpes lagopus) population is endangered due to overharvest and competition with the larger red fox (Vulpes vulpes). In this study, we have screened the population in Sweden for endoparasites by analysis of non-invasively faecal samples collected at reproductive dens during two summers, one with low food abundance (2008) and the other with high food abundance (2010). Eggs, larvae and oocysts of a total of 14 different endoparasites were identified with a species richness per inhabited den of $3.2(\mathrm{CI} 95 \% \pm 0.48)$ in 2008 and $2.7(\mathrm{CI} 95 \% \pm 0.72)$ in 2010. Capillariidae-like eggs was identified at $59 \%$ of the dens in 2008 and $57 \%$ in 2010 and Toxocara canis with 7\% (2008) and 30\% (2010); Toxascaris leonina with $93 \%$ (2008) and 65\% (2010); Uncinaria stenocephala 65\% (2008) and 39\% (2010); Crenosoma vulpis 3\% (2008) and 4\% (2010); Trichuris sp. 7\% (2008) and 4\% (2010); Cystoisospora canis-like
\end{abstract}

Communicated by C. Gortázar

T. Meijer $(\bowtie) \cdot$ A. Angerbjörn

Department of Zoology, Stockholm University,

10691 Stockholm, Sweden

e-mail: tomas.meijer@zoologi.su.se

R. Mattsson · X. Fernández-Aguilar · D. Gavier-Widén

Department of Pathology and Wildlife Diseases,

National Veterinary Institute (SVA),

75189 Uppsala, Sweden

E. Osterman-Lind

Department of Virology, Immunobiology and Parasitology,

National Veterinary Institute (SVA),

75189 Uppsala, Sweden

D. Gavier-Widén

Department of Biomedical Sciences and Veterinary,

Public Health University of Agricultural Sciences (SLU),

75189 Uppsala, Sweden oocysts 28\% (2008) and 26\% (2010); Cystoisospora ohiensis-like oocysts 38\% (2008) and 4\% (2010); Eimeria sp. 7\% (2008) and 9\% (2010); Sarcocystis sp. 3\% (2008) and 9\% (2010); Taenia sp. 10\% (2008) and 4\% (2010); Mesocestoides sp. 3\% (2008) and 0\% (2010); Balantidium sp. 0\% (2008) and 9\% (2010) and Spiruroidea-like eggs $0 \%$ (2008) and 4\% (2010). To our knowledge, Balantidium sp., Sarcocystis sp. and Trichuris sp. has never been described before in wild arctic foxes.

Keywords Alopex lagopus · Parasites · Conservation · Wildlife disease $\cdot$ Sweden

\section{Introduction}

Endoparasite helminth infections have been found to be an important component in the dynamics of wild mammal populations. Effects on vital demographic parameters such as decreased survival and fecundity have been described (Anderson and May 1978). From a conservation perspective, endoparasite infections might thus hamper population recovery or decrease the efficiency of conservation actions. In Fennoscandia, the arctic fox (Vulpes lagopus) population suffered a severe demographic and genetic bottleneck during the twentieth century (Nyström et al. 2006) due to overharvest and increased competition with the larger red fox (Vulpes vulpes; Hersteinsson et al. 1989). Since 1998, the conservation project, "Save the Endangered Fennoscandian Alopex", has conducted conservation actions to increase the viability of the population. The actions include supplementary feeding to increase juvenile survival and red fox culling to decrease interference competition (Angerbjörn et al. 2008). Despite management actions, the juvenile and adult survival in Fennoscandia is lower compared to other small canids 
(Meijer et al. 2008). The arctic fox population in Fennoscandia is highly dependent upon small rodent cycle for reproduction and survival (Angerbjörn et al. 1995). Between the small rodent peaks, food is scarce and endoparasite infections might be one possible factor contributing to the lower survival. In this study, we investigated the species richness of endoparasites in the arctic fox population in Sweden by analysis of non-invasively collected faecal samples during 2 years, one with high small rodent abundance and one with low rodent abundance. Samples were included from two summers since endoparasites can be variable over time and change with food abundance (e.g., Saeed et al. 2006). Approximately, $90 \%$ of the recorded arctic fox litters in Sweden were screened for endoparasites in the study.

\section{Materials and methods}

The samples were collected in the Swedish part of the mountain tundra in Jämtland, Västerbotten and Norrbotten Counties. Fresh faecal pellets were collected during JulyAugust 2008 and 2010 at reproductive den sites with arctic foxes. The samples originated from both juvenile and adult arctic foxes in order to describe the species richness of endoparasites at den/litter level. In 2008, the small rodent abundance was low, and in 2010, it was high. In total, 29 dens with litters were sampled in 2008 and 23 in 2010; this represents $90 \%$ of all litters born in Sweden 2008 and 2010.

Parasitological examinations of the faecal samples were conducted at the National Veterinary Institute, Uppsala, Sweden. Analyses were performed using a flotation technique with centrifugation according to Thienpont et al. (1986), but with a few modifications. Three grammes of faeces were mixed with $10 \mathrm{ml}$ of saline and sieved into a test tube which was centrifuged. All samples were also analysed with a modified Telemann sedimentation technique (Thienpont et al. 1986), where $3 \mathrm{~g}$ of faeces and $10 \mathrm{ml}$ acetic acid solution were mixed and sieved into a test tube before the addition of ether and centrifugation. Parasite eggs and oocysts were identified morphologically according to Thienpont et al. (1986) and Pellérdy (1974). We used Fisher's exact test to detect differences in proportion infected litters/dens between years.

\section{Results}

Parasitological analysis of the faecal samples revealed eggs, larvae and oocysts of a total of 14 different endoparasites (Table 1), including seven nematode species: Capillariidae-like eggs, Toxocara canis, Toxascaris leonina, Uncinaria stenocephala, Crenosoma vulpis, Trichuris sp., Spiruroidea-like eggs; five protozoan species: Cystoisospora ohioensis-like oocysts, Cystoisospora canis-like oocysts, Balantidium sp., Eimeria sp. and Sarcocystis sp. and two cestodes: Taenia sp. and Mesocestoides $\mathrm{sp}$. Species richness per inhabited den was 3.2 $(\mathrm{CI} 95 \% \pm 0.48)$ in 2008 and $2.7(\mathrm{CI} 95 \% \pm 0.72)$ in 2010 $(p=0.21)$.

T. leonina was the most frequent parasite species found at $93 \%$ of the dens in 2008 and $65 \%$ in 2010 (Table 1.). $C$. canis-like oocysts, U. stenocephala and Capillariidae-like
Table 1 Parasite species and richness (\%) at arctic fox (V. lagopus) den sites $(n)$ with litters in 2008 and 2010

$X$ indicates that the species was identified

${ }^{\mathrm{a}}$ from Aguirre et al. (2000), Sweden

\begin{tabular}{|c|c|c|c|c|c|}
\hline Endoparasite & $\begin{array}{l}2008 \\
(n=29)\end{array}$ & $\begin{array}{l}2010 \\
(n=23)\end{array}$ & Trend & $\begin{array}{l}\text { Fisher exact test } \\
(p \text { value })\end{array}$ & $\begin{array}{l}1996 \\
(n=3)^{\mathrm{a}}\end{array}$ \\
\hline \multicolumn{6}{|l|}{ Protozoa } \\
\hline Balantidium sp. & 0 & 9 & + & 0.19 & \\
\hline Cystoisospora canis-like oocysts & 28 & 26 & - & 0.57 & $\mathrm{X}$ \\
\hline Cystoisospora ohiensis-like oocysts & 38 & 4 & -- & 0.01 & $\mathrm{X}$ \\
\hline Eimeria sp. & 7 & 9 & + & 0.6 & $\mathrm{X}$ \\
\hline Sarcocystis sp. & 3 & 9 & + & 0.41 & \\
\hline \multicolumn{6}{|l|}{ Nematoda } \\
\hline Capillariidae-like eggs & 59 & 57 & 0 & 0.51 & $\mathrm{X}$ \\
\hline Toxocara canis & 7 & 30 & ++ & 0.03 & $\mathrm{X}$ \\
\hline Toxascaris leonina & 93 & 65 & - & 0.01 & $\mathrm{X}$ \\
\hline Uncinaria stenocephala & 65 & 39 & - & 0.05 & $\mathrm{X}$ \\
\hline Crenosoma vulpis & 3 & 4 & 0 & 0.69 & $\mathrm{X}$ \\
\hline Trichuris sp. & 7 & 4 & - & 0.58 & \\
\hline Spiruroidea-like eggs & 0 & 4 & + & 0.44 & \\
\hline \multicolumn{6}{|l|}{ Cestoda } \\
\hline Taenia sp. & 10 & 4 & - & 0.39 & \\
\hline Mesocestoides sp. & 3 & 0 & - & 0.55 & \\
\hline
\end{tabular}


eggs were all found in relatively high abundance during both 2008 and 2010 (Table 1). C. ohioensis-like oocysts were found at $38 \%$ of the den sites in 2008 but only at $4 \%$ in 2010. T. canis showed the opposite pattern compared to C. ohioensis-like oocysts and increased from $7 \%$ in 2008 to $30 \%$ in 2010 . The other parasite species were all found in $10 \%$ of the dens or less.

\section{Discussion}

The species richness identified in this study is similar to previous studies of arctic foxes in Fennoscandia (Aguirre et al. 2000), Greenland (Kapel and Nansen 1996) and Iceland (Skirnisson et al. 1993), even though the species composition differs between the areas (Table 2.). Most notable is the
Table 2 Endoparasite species identified in the arctic fox from Sweden (Aguirre et al. 2000, this study), Iceland (Skirnisson et al. 1993), Greenland (Kapel and Nansen 1996; Rausch et al. 1983), Canada (Eaton and Secord 1979) and Svalbard (Stien et al. 2002)

\begin{tabular}{|c|c|c|c|c|c|}
\hline & Sweden & Iceland & Greenland & Canada & Svalbarc \\
\hline \multicolumn{6}{|l|}{ Cestoda } \\
\hline Taenia crassiceps & & & & $\mathrm{x}$ & $\mathrm{x}$ \\
\hline Taenia ovis krabbei & & & $\mathrm{x}$ & & $\mathrm{x}$ \\
\hline Taenia sp. & $\mathrm{x}$ & & $\mathrm{x}$ & & \\
\hline Taenia polyacantha & & & & & $\mathrm{x}$ \\
\hline Mesocestoides canislagopodis & & $\mathrm{x}$ & & & $\mathrm{x}$ \\
\hline Mesocestoides lineatus & & & $\mathrm{x}$ & & \\
\hline Mesocestoides sp. & $\mathrm{x}$ & & & & \\
\hline $\begin{array}{l}\text { Diphyllobothrium dendriticum } \\
\text { and Diphyllobothrium sp. }\end{array}$ & & $\mathrm{x}$ & $\mathrm{x}$ & & $\mathrm{x}$ \\
\hline Schistocephalus solidus & & $\mathrm{x}$ & & & \\
\hline Echinococcus multilocularis & & & & $\mathrm{x}$ & $\mathrm{x}$ \\
\hline \multicolumn{6}{|l|}{ Nematoda } \\
\hline Ascarioid nematodes ${ }^{\mathrm{a}}$ & & & & & $\mathrm{x}$ \\
\hline Capillariidae aerophila & & $\mathrm{x}$ & & & \\
\hline Capillariidae-like eggs & $\mathrm{x}$ & & & & \\
\hline Toxascaris leonina & $\mathrm{x}$ & $\mathrm{x}$ & $\mathrm{x}$ & $\mathrm{x}$ & \\
\hline Toxocara canis & $\mathrm{x}$ & $\mathrm{x}$ & & & \\
\hline Uncinaria stenocephala & $\mathrm{x}$ & $\mathrm{x}$ & $\mathrm{x}$ & & \\
\hline Crenosoma vulpis & $\mathrm{x}$ & & & & \\
\hline Trichuris sp. & $\mathrm{x}$ & & & & \\
\hline Spiruroidea-like eggs & $\mathrm{x}$ & & & & \\
\hline Strongyloides stercoralis & & & $\mathrm{x}$ & & \\
\hline \multicolumn{6}{|l|}{ Protozoa } \\
\hline Balantidium sp. & $\mathrm{x}$ & & & & \\
\hline Cystoisospora canis-like oocysts & $\mathrm{x}$ & & & & \\
\hline Eimeria sp. & $\mathrm{x}$ & $\mathrm{x}$ & & & \\
\hline Sarcocystis sp. & $\mathrm{x}$ & & & & \\
\hline Acanthocephala & & & & & $\mathrm{x}$ \\
\hline \multicolumn{6}{|l|}{ Acanthocephalan $^{\mathrm{a}}$} \\
\hline Corynosoma hadweni & & $\mathrm{x}$ & & & \\
\hline Polymorphus meyeri & & $\mathrm{x}$ & & & \\
\hline Polymorphus sp. & & & $\mathrm{x}$ & & \\
\hline \multicolumn{6}{|l|}{ Trematoda } \\
\hline Tristriata $\mathrm{sp}$ & & $\mathrm{x}$ & & & \\
\hline Spelotrema sp. & & $\mathrm{x}$ & & & \\
\hline Brachylaemus sp. & & $\mathrm{x}$ & & & \\
\hline Plagiorchis elegans & & $\mathrm{x}$ & $\mathrm{x}$ & & \\
\hline Cryptocotyle concavum & & & $\mathrm{x}$ & & \\
\hline Cryptocotyle lingua & & $\mathrm{x}$ & & & \\
\hline Cryptocotyle sp. & & & $\mathrm{x}$ & & \\
\hline Echinoparyphium sp. & & & $\mathrm{x}$ & & \\
\hline
\end{tabular}


absence of Acanthocephalans and trematodes in Sweden, Canada and Svalbard compared to Iceland and Greenland (Table 2). This is likely due to dietary differences between coastal foxes and inland foxes where the coastal foxes prey upon marine resources and inland foxes depend on small rodents or birds. In Iceland, no trematodes were found in the inland foxes but were common among coastal foxes (Skirnisson et al. 1993). According to Wilson et al. (2003), low density of host populations may have a negative impact on the parasite species richness. This implies a prediction that the small Fennoscandian arctic fox population with a recent population bottleneck (Nyström et al. 2006) should host fewer species of endoparasites compared to larger populations as in, e.g. Iceland and Greenland. In Fennoscandia, the arctic fox is sympatric with the red fox which might function as an endoparasite reservoir and explains the high number of endoparasites despite the small population size. Trichuris sp., Sarcocystis sp. and Balantidium sp. have to our knowledge, never been described in wild arctic foxes but Trichuris sp. and Sarcocystis sp. are common in the red fox (Persson and Christensson 1971; Rajkovic-Janje et al. 2004). Except for the C. ohioensis-like oocysts and Balantidium sp., all the endoparasite species identified in the arctic fox have previously also been described in the red fox (Persson and Christensson 1971; Martinez-Carrasco et al. 2007a; Rajkovic-Janje et al. 2002; Rajkovic-Janje et al. 2004; Rodriguez and Carbonell 1998). In addition, the number of identified endoparasite species in the Fennoscandian arctic fox population is most likely underestimated in this study since analysis of faecal samples only can detect species that sheds eggs during the sampling period. Especially cestodes have been found to be difficult to detect in faecal samples (Martínez-Carrasco et al. 2007b).

Comparisons of the parasite species richness between 2008 and 2010 indicate a stable number of species in the arctic fox population. The most common species in our study was also found in Aguirre et al. (2000) that recorded endoparasites of three litters in Sweden 1996. Even though the species richness seems to be fairly stable over time, the proportion of infected dens is more variable (Table 1). T. canis was the only parasite that significantly increased from $7 \%$ to $30 \%$ between 2008 and 2010 which could be explained by the increase of small rodents, possible function as an indirect paratenic host (Taylor et al. 2007). However, this seems not to be a general phenomenon since T. leonina, $U$. stenocephala and $C$. ohiensis-like oocysts all decreased despite that they all can be spread by small rodents (Taylor et al. 2007). Several of the other identified parasite species are likely to be spread by small rodents but they all remained at a stable level between the sampling years. Monitoring over several years would be needed for further conclusions about the endoparasite dynamics in the arctic fox.
The impact of the identified parasites on the population might be variable due to large variations in natural food resources. The parasite burden can have effects on both survival and lactation levels in other mammal species (Gulland 1992; Albon et al. 2002). The most common endoparasite species in this study, C. ohioensis-like oocysts, C.canis-like oocysts, Capillariidae-like eggs, T. leonina and $U$. stenocephala, have all been observed to have a negative impact on their host (Taylor et al. 2007). Aguirre et al. (2000) found a negative relationship between hind foot length and infection of $T$. leonina with a possible negative effect on future reproduction. However, in the study population, the foxes have been supplementary fed (Angerbjörn et al. 2008), which might reduce possible negative effects of the endoparasites by the extra energy provided in the food. Only few cases of juvenile mortality due to starvation have been observed in the area where the foxes have received supplementary food (Meijer et al. 2008; Meijer et al. 2010). Earlier studies of arctic foxes showed that non-fed litters were found to suffer from higher mortality due to starvation (Tannerfeldt et al. 1994). In the study area, the juvenile summer mortality has been found to be $27 \%$ (Meijer et al. 2010) with an annual mortality of $92 \%$ during the first year (Meijer et al. 2008). A large proportion of the summer mortality has been attributed to predation (Meijer et al. 2010), but the cause of mortality after natal dispersal is yet unknown. Endoparasites might contribute to the high mortality rate, especially since the juveniles lose their access to supplementary food after dispersing. The juvenile body weight has been found to be highly variable in the study area but seems to be related to maternal experience and date of birth (Meijer et al. 2010). From a conservation perspective, it is of importance to consider the impacts of endoparasite infections if supplementary feeding is reduced or suspended.

Acknowledgements The County board administration in Jämtland with L. Liljemark, H. Berglund and L. Back. This study was financed by Swedish environmental protection agency, EU LIFE (SEFALO+), WWF Sweden, Fjällräven AB, International Polar Year and with logistical support from Swedish Polar Research Secretary and the Swedish research council.

\section{References}

Aguirre A, Angerbjörn A, Tannerfeldt M, Mörner T (2000) Health evaluation of arctic fox (Alopex lagopus) cubs in Sweden. J Zoo Wildl Med 31:36-40

Albon SD, Stien A, Irvine RJ, Langvatn R, Ropstad E, Halvorsen O (2002) The role of parasites in the dynamics of a reindeer population. Proc R Soc Lond B Biol 269:1625-1632

Anderson RM, May RM (1978) Regulation and stability of hostparasite population interactions 1. Regulatory processes. J Anim Ecol 47:219-247 
Angerbjörn A, Tannerfeldt M, Bjärvall A, Ericson M, From J, Noren E (1995) Dynamics of the arctic fox population in Sweden. Ann Zool Fenn 32:55-68

Angerbjörn A, Henttonen H, Eide NE, Landa A, Norén K, Meijer T (2008) SEFALO+. Final report LIFE03 NAT/S/000073 Saving the Endangered Fennoscandian Alopex lagopus.

Eaton RDP, Secord DC (1979) Some intestinal parasites of arctic fox, Banks island, N.W.T. Can J Comp Med 43:229-230

Gulland FMD (1992) The role of nematode parasites in soay sheep (Ovis aries L) mortality during a population crash. Parasitol 105:493-503

Hersteinsson P, Angerbjörn A, Frafjord K, Kaikusalo A (1989) The arctic fox in Fennoscandia and Iceland-management problems. Biol Conserv 49:67-81

Kapel CMO, Nansen P (1996) Gastrointestinal helminths of arctic foxes (Alopex lagopus) from different bioclimatological regions in Greenland. J Parasitol 82:17-24

Martinez-Carrasco C, de Ybanez MRR, Sagarminaga JL, Garijo MM, Moreno F, Acosta I, Hernandez S, Alonso FD (2007) Parasites of the red fox (Vulpes vulpes Linnaeus, 1758) in Murcia, Southeast Spain. Rev Med Vet 158:331-335

Martínez-Carrasco C, Berriatua M, Garijo E, Martínez J, Alonso FD, Ruiz de Ybáñez R (2007b) Epidemiological study of nonsystematic parasitism in dogs in southeast mediterranean Spain assessed by Coprological and Post-mortem Examination. Zoonoses Public Hlth., 54

Meijer T, Norén K, Hellström P, Dalén L, Angerbjörn A (2008) Estimating population parameters in a threatened arctic fox population using molecular tracking and traditional field methods. Anim Conserv 11:330-338

Meijer T, Norén K, Angerbjörn A (2010) The impact of maternal experience on post-weaning survival in an endangered arctic fox population. Eur J Wildl Res. doi:10.1007/s10344-010-0463-0

Nyström V, Angerbjörn A, Dalén L (2006) Genetic consequences of a demographic bottleneck in the Scandinavian arctic fox. Oikos 114:84-94

Pellérdy L (1974) Coccidia and coccidiosis, 2nd edn. Verlag paul Parey, Berlin, p 959
Persson L, Christensson D (1971) Endoparasiter hos rödräv i Sverige. Zoologisk Vilt Revy 1-2:17-28

Rajkovic-Janje R, Marinculic A, Bosnic S, Benic M, Vinkovic B, Mihaljevic Z (2002) Prevalence and seasonal distribution of helminth parasites in red foxes (Vulpes vulpes) from the Zagreb County (Croatia). Z Jagdwiss 48:151-160

Rajkovic-Janje R, Sabolic M, Bosnic S, Auslender V (2004) Sarcocystis $\mathrm{sp}$ in red foxes (Vulpes vulpes) from Northern Croatia. Eur J Wildl Res 50:95-96

Rausch RL, Fay FH, Williamson FSL (1983) Helminths of the arctic fox, Alopex lagopus (L), in Greenland. Can J Zool 61:1847-1851

Rodriguez A, Carbonell E (1998) Gastrointestinal parasites of the Iberian lynx and other wild carnivores from Central Spain. Acta Parasitol 43:128-136

Saeed I, Maddox-Hyttel C, Monrad J, Kapel CMO (2006) Helminths of red foxes (Vulpes vulpes) in Denmark. Vet Parasitol 139:168-179

Skirnisson K, Eydal M, Gunnarsson E, Hersteinsson P (1993) Parasites of the arctic fox (Alopex lagopus) in Iceland. J Wildl Dis 29:440-446

Stien A, Irvine RJ, Ropstad E, Halvorsen O, Langvatn R, Albon SD (2002) The impact of gastrointestinal nematodes on wild reindeer: experimental and cross-sectional studies. J Anim Ecol 71:937-945

Tannerfeldt M, Angerbjörn A, ArvidSon B (1994) The effect of summer feeding on juvenile arctic fox survival — a field experiment. Ecography 17:88-96

Taylor MK, Coop RL, Wall RL (2007) Veterinary parasitology. Blackwell Publishing, Oxford

Thienpont D, Rochette F, Vanparjis OFJ (1986) Diagnosing helminthiasis by coprological examination, 2nd edn. Jansen Research Foundation, Beerse, p 205

Wilson K, Bjornstad ON, Dobson AP, Arneberg P, Begon M, Cattadori IM, Greenman JV, Heesterbeek H, Hudson PJ, Newborn D, Pugliese A, Rizzoli A, Rosà R, Rosso F (2003) In: Hudson Pj, Rizzoli A, Grenfell BT, Heesterbeek H, Dobson AP (eds) Heterogeneities in macroparasite infections; patterns and processes. The ecology of wildlife diseases. Oxford University Press, Oxford, pp 6-44 